\title{
Peripheral odontogenic keratocyst: Report of two new cases and review of the literature
}

\author{
Bruno-Teixeira-Gonçalves Rodrigues ${ }^{1}$, Mônica-Simões Israel ${ }^{2}$, Kenia-Lorena-Monteiro de Moura ${ }^{3}$, Giulian- \\ na-Lima Pinheiro ${ }^{4}$, Roman Carlos ${ }^{5}$, Fábio-Ramoa Pires ${ }^{6}$ \\ ${ }^{1}$ DDS, Dental School, State University of Rio de Janeiro, Rio de Janeiro, Brazil \\ ${ }^{2}$ DDS, PhD, Stomatology, Department of Diagnosis and Therapeutics, Dental School, State University of Rio de Janeiro, Rio de \\ Janeiro, Brazil \\ ${ }^{3}$ DDS, Post-graduation in Orthodontics, Dental School, State University of Rio de Janeiro, Rio de Janeiro, Brazil \\ ${ }^{4}$ DDS, Post-graduation in Oral and Maxillofacial Surgery, Clementino Fraga Filho Hospital, Federal University of Rio de Janeiro, \\ Rio de Janeiro, Brazil \\ ${ }^{5}$ DDS, Pathology Department, Integra Cancer Center, Guatemala City, Guatemala \\ ${ }^{6} \mathrm{DDS}, \mathrm{PhD}$, Oral Pathology, Dental School, State University of Rio de Janeiro, Rio de Janeiro, Brazil
}

Correspondence:

Oral Pathology, Dental School

State University of Rio de Janeiro

Av. 28 de setembro, 157 - Vila Isabel

CEP: 20551-030 - Rio de Janeiro/RJ - Brazil

ramoafop@yahoo.com

Rodrigues BTG, Israel MS, de Moura KLM, Pinheiro GL, Carlos R, Pires FR. Peripheral odontogenic keratocyst: Report of two new cases and review of the literaturea. J Clin Exp Dent. 2020;12(10):e1005-10.

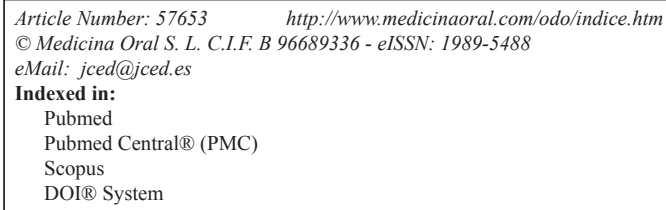

\begin{abstract}
Peripheral odontogenic keratocyst (POKC) is a rare soft tissue entity showing the same histological characteristics of odontogenic keratocyst. Herein, we report two cases of POKC affecting the gingiva/alveolar mucosa. Case 1. A 43-year-old female was referred for evaluation of a painless well-defined nodular, sessile, non-tender swelling in the right maxillary buccal gingiva. No radiological alterations were observed. The patient was submitted to excisional biopsy and histological diagnosis was POKC. There were no signs of local recurrence after a 4-year follow-up. Case 2. A 63-year-old female was referred for evaluation of a painless well-defined nodular, sessile, yellowish swelling in the anterior mandibular alveolar mucosa. No radiological alterations were observed. The patient was submitted to excisional biopsy and histological diagnosis was POKC. Patient recovery was uneventful but she did not return for follow-up. POKC should be considered in the differential diagnosis of gingival cystic swellings and can be managed through conservative surgery.
\end{abstract}

Key words: Odontogenic keratocyst, peripheral, gingiva, alveolar mucosa.

\section{Introduction}

Odontogenic keratocyst (OKC), a potentially aggressive odontogenic cyst, accounts for $12-14 \%$ of all odontogenic cysts and show a predilection for the posterior mandible $(1,2)$. However, on rare occasions, OKC can affect only the soft tissues, with predilection for the gingival/alveolar mucosa. In these rare extraosseous cases, the term peripheral odontogenic keratocyst (POKC) has 
been applied (3). Therefore, we report two rare cases of POKC affecting the right maxillary gingiva and the anterior mandibular alveolar mucosa, both managed through a conservative surgical approach.

\section{Case Report}

\section{-Case 1}

A 43-year-old woman was referred for evaluation of a 4-year lasting oral swelling in the right maxilla. Medical history was non-contributory and the patient denied any tobacco or alcohol consumption. Extraoral clinical examination showed no alterations. Intraoral clinical examination revealed the presence of a single painless well-defined nodular, sessile, non-tender swelling covered by normal oral mucosa, measuring $15 \mathrm{~mm}$ and located in the in the upper right buccal gingiva between the second premolar (\#15) and first molar (\#16) (Fig.1A). Both teeth were vital and panoramic and periapical radiographs showed no alterations in the area (Fig. 1B,C). Clinical diagnosis was gingival cyst of the adult and an excisional biopsy was performed under local anesthesia (Fig. 1D). During the surgery a slight superficial bone resorption was observed, but there was no rupture of the cortical bone, confirming the location of the lesion exclusively in the soft tissues of the area.

The specimen was immersed in 10\% formaldehyde and sent for histological analysis (Fig. 2A). Hematoxylin and eosin stained $5 \mu \mathrm{m}$ histological sections showed a fragment of oral mucosa covered by parakeratinized stratified squamous epithelium. In the adjacent connective tissue a cystic cavity filled by keratin and covered by a regular uniform parakeratinized stratified squamous epithelium with corrugated surface and a basal cell layer with a palisaded pattern was observed (Fig. 2B). The cystic cavity was located just beneath the surface epithelium and no bone fragments were observed. Due to the clinical, radiological, transoperatory and histological features a diagnosis of POKC was established. Patient recovery was uneventful and a four month follow-up showed complete clinical repair in the area (Fig. $2 \mathrm{C}$ ). The patient remained in clinical and radiological follow-up and there are no signs of local recurrence in a four-year clinical follow-up (Fig. 2D).

-Case 2

A 63-year-old woman was referred for evaluation of an 18-month lasting oral swelling in the anterior mandibular alveolar mucosa. The patient reported controlled arterial hypertension. Extraoral clinical examination showed no alterations. Intraoral clinical examination revealed the presence of an asymptomatic single elevated lesion, covered by intact smooth surface mucosa, tense on palpation, with a yellowish coloration, measuring 10 $\mathrm{mm}$ in the lower alveolar mucosa between the central incisors (\#31 and \#41) (Fig. 3A). Both teeth were vital and a periapical radiograph showed no alterations in the area (Fig. 3B). Clinical diagnosis was gingival cyst of

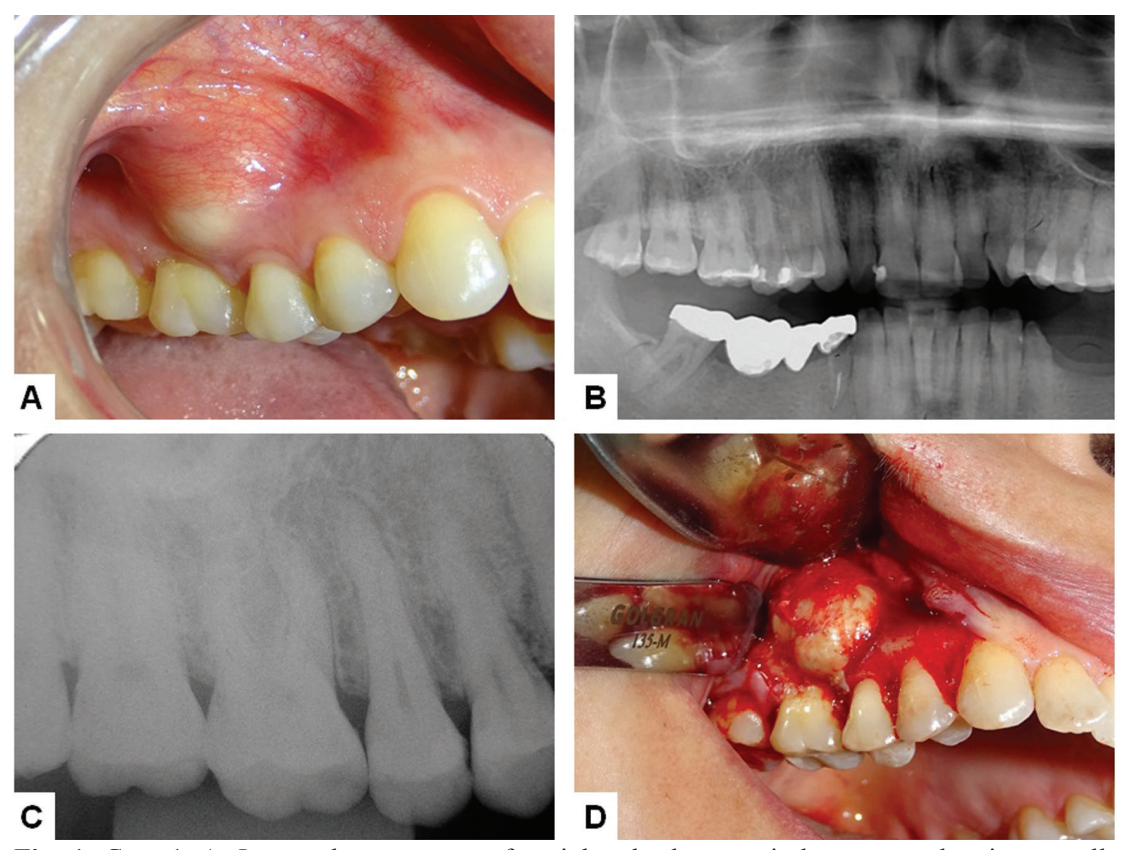

Fig. 1: Case 1. A. Intraoral appearance of peripheral odontogenic keratocyst showing a welldefined nodular sessile swelling covered by normal oral mucosa in the upper right buccal gingiva between the second premolar and first molar. B. Panoramic radiograph showing no bone alterations in the right maxillary bone. C. Periapical radiograph showing no bone alterations in the area of the second premolar and first molar. D. Transoperative aspect showing a well-defined yellowish lesion superimposed to the cortical bone. 

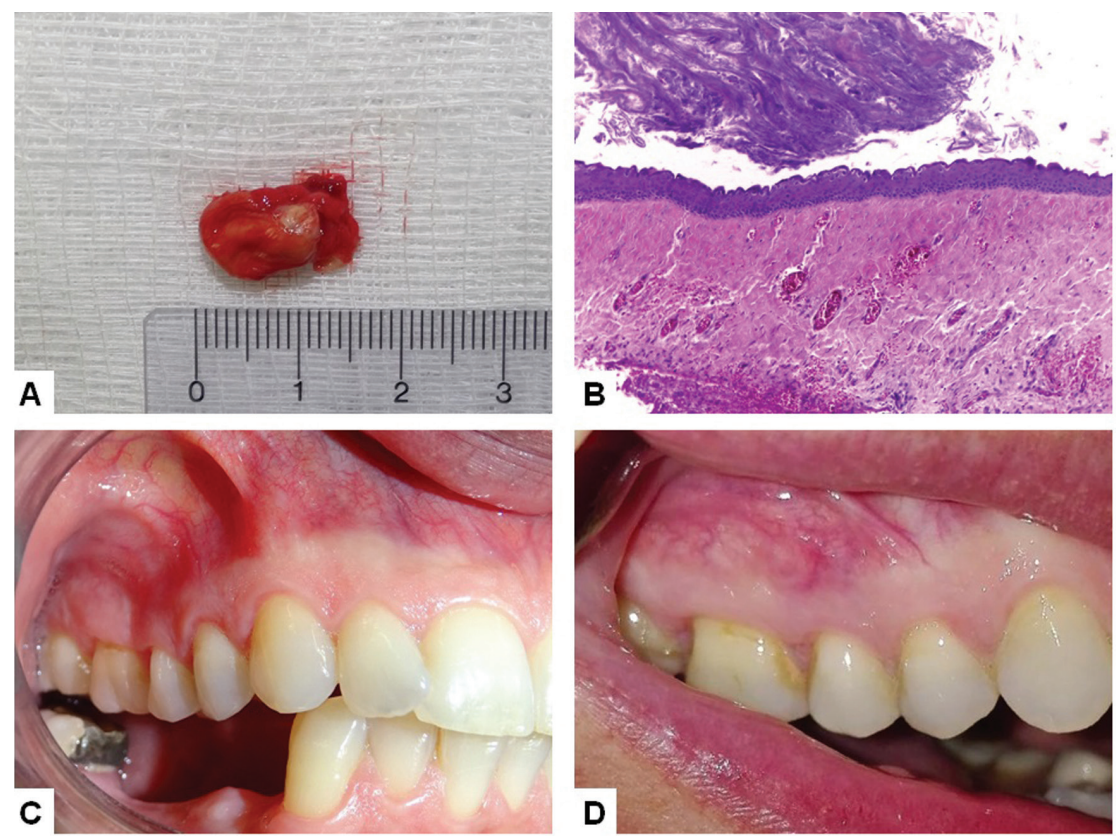

Fig. 2: A. Gross image showing the yellowish content of the lesion. B. Histological features of the lesion showing a cystic cavity filled by keratin and lined by a parakeratinized stratified squamous epithelium with corrugated surface and polarized basal cell layer (HE, 100x). C. Postoperative aspect after a four-month follow-up, showing complete clinical repair in the area. D. Clinical aspect in a 4-year follow-up, showing no signs of local reccurence.
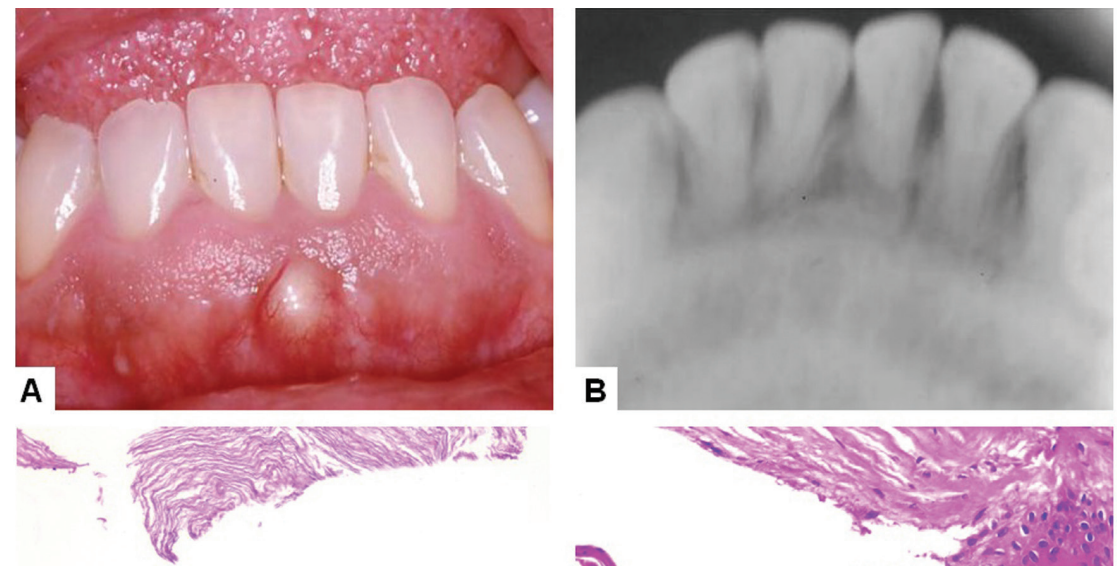

B
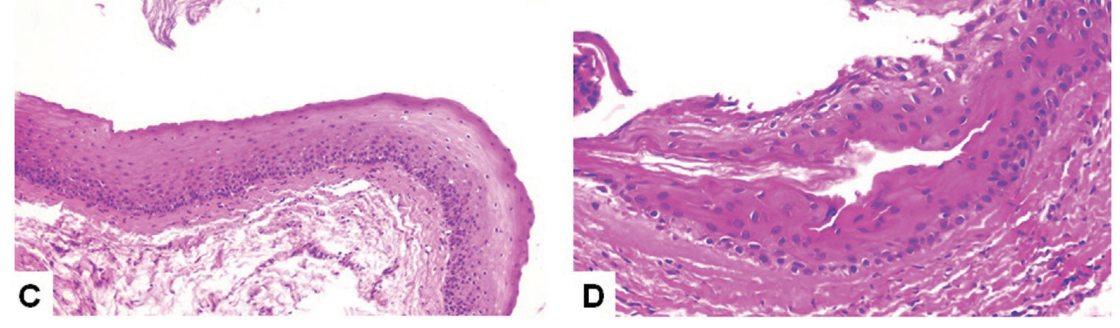

Fig. 3: Case 2. A. Intraoral appearance of peripheral odontogenic keratocyst showing a welldefined sessile swelling covered by normal oral mucosa in the lower anterior alveolar mucosa between central incisors. B. Periapical radiograph showing no bone alterations in the area. $\mathrm{C}$ and D. Histological features of the lesion showing a cystic cavity filled by keratin and lined by a parakeratinized stratified squamous epithelium with corrugated surface and polarized basal cell layer (C - HE, 100x; D - HE, 200x). 
the adult and an excisional biopsy was performed under local anesthesia. During the surgery, cortical bone was intact and no central bone involvement was observed.

The specimen was immersed in 10\% formaldehyde and sent for histological analysis. Hematoxylin and eosin stained $5 \mu \mathrm{m}$ histological sections showed a cystic cavity filled by keratin and covered by a regular uniform parakeratinized stratified squamous epithelium with corrugated surface and a basal cell layer with a palisaded pattern (Fig. 3C,D). Due to the clinical, radiological, transoperatory and histological features a diagnosis of POKC was established. Patient recovery after one week was uneventful but she did not return for further follow-up.

We state that we have followed the Helsinki declaration and that written permission was obtained from both patients included in the present report.

\section{Discussion}

$\mathrm{OKC}$ is a benign odontogenic cyst that shows some unique characteristics such as its typical histological pattern, potential for local infiltration and higher rates of local recurrence when compared with other odontogenic cysts $(1,2)$. The condition has a slight predilection for males and most patients are in the second to fourth decades of life. The most common anatomical location for $\mathrm{OKC}$ is the posterior mandible and it presents as a we1l-defined unilocular or multilocular radiolucency. OKC usually appear as a solitary lesion but some sporadic cases can be associated to the nevoid basal cell carcinoma syndrome (Gorlin-Goltz syndrome) $(1,2)$.

In very rare instances $\mathrm{OKC}$ can present as an extraosseous soft tissue lesion with no involvement of the adjacent bone. POKC is expected to represent less than $0,5 \%$ of all $\mathrm{OKCs}$, and 35 cases have been reported in the indexed English-language literature up to now (Table I) (3-24). Most cases (22 - 63\% - including the present ones) affected the gingival/alveolar mucosa, with predilection for the upper buccal region from incisors to premolars (Table 1, 1 cont.). Furthermore, POKC shows a slight male prevalence $(1.1: 1)$ and affect patients with a mean of 52 years (ranging from 16 to 83 years old); it usually presents as a soft tissue swelling measuring from 3 to $5 \mathrm{~mm}(3-24)$. The present cases have some interes-

Table 1: Peripheral odontogenic keratocysts reported in the English-language literature from 1975 to now.

\begin{tabular}{|c|c|c|c|c|c|}
\hline Author & Year & Age & Gender & Site & Follow-up (months) * \\
\hline Stoelinga et al. (4) ** & 1975 & - & - & Maxillary gingiva & NS \\
\hline Buchner and Hansen (5) & 1979 & - & - & $\begin{array}{l}\text { Buccal mucosa } \\
\text { Buccal mucosa }\end{array}$ & $\begin{array}{l}\text { NS } \\
\text { NS }\end{array}$ \\
\hline Dayan et al. (6) & 1988 & 42 & M & Left maxillary gingiva & No recurrence (10) \\
\hline Chehade et al. (7) & 1994 & $\begin{array}{l}37 \\
66 \\
35 \\
70 \\
57 \\
42\end{array}$ & $\begin{array}{l}\mathrm{M} \\
\mathrm{F} \\
\mathrm{F} \\
\mathrm{M} \\
\mathrm{F} \\
\mathrm{M}\end{array}$ & $\begin{array}{l}\text { Right mandibulary gingiva } \\
\text { Left maxillary gingiva } \\
\text { Mandibular gingiva } \\
\text { Left mandibular gingiva } \\
\text { Right maxillary gingiva } \\
\text { Right mandibulary gingiva }\end{array}$ & $\begin{array}{l}\text { NS } \\
\text { NS } \\
\text { NS } \\
\text { NS } \\
\text { NS } \\
\text { NS }\end{array}$ \\
\hline Fardal and Johannessen (8) & 1994 & 41 & $\mathrm{~F}$ & Mandibular and maxillary gingiva & NS \\
\hline Ide et al. (9) & 2002 & $\begin{array}{l}38 \\
46\end{array}$ & $\begin{array}{l}\mathrm{F} \\
\mathrm{F}\end{array}$ & $\begin{array}{l}\text { Left maxillary gingiva } \\
\text { Right maxillary gingiva }\end{array}$ & $\begin{array}{l}\text { No recurrence }(60) \\
\text { No recurrence }(72)\end{array}$ \\
\hline Chi et al. (10) & 2005 & $\begin{array}{l}81 \\
64\end{array}$ & $\begin{array}{l}\mathrm{F} \\
\mathrm{F}\end{array}$ & $\begin{array}{l}\text { Left maxillary gingiva } \\
\text { Left maxillary gingiva }\end{array}$ & $\begin{array}{c}\text { Recurrence (6) } \\
\text { No recurrence (21) }\end{array}$ \\
\hline Preston and Narayana (11) & 2005 & 83 & $\mathrm{~F}$ & Left maxillary gingiva & No recurrence (6) \\
\hline Ide et al. (12) & 2008 & 53 & M & Left mandibular gingiva & No recurrence $(84)$ \\
\hline Faustino et al. (3) & 2008 & 57 & $\mathrm{~F}$ & Left mandibular gingiva & Recurrence (12) \\
\hline Precheur and Krolls (13) & 2009 & 59 & M & Right buccal space & NS \\
\hline Ide et al. (14) & 2010 & $\begin{array}{l}60 \\
16\end{array}$ & $\begin{array}{l}\mathrm{M} \\
\mathrm{M}\end{array}$ & $\begin{array}{l}\text { Left buccal mucosa } \\
\text { Right buccal mucosa }\end{array}$ & $\begin{array}{c}\text { No recurrence (NS) } \\
\text { NS }\end{array}$ \\
\hline Vij et al. (15) & 2011 & 56 & M & Left maxillary gingiva & NS \\
\hline Gröbe et al. (16) & 2012 & 52 & M & Buccal mucosa & No recurrence (4) \\
\hline Kaminagakura et al. (17) & 2013 & 37 & M & Left buccal mucosa & No recurrence (12) \\
\hline
\end{tabular}


Table 1 cont.: Peripheral odontogenic keratocysts reported in the English-language literature from 1975 to now.

\begin{tabular}{|c|c|c|c|c|c|}
\hline Yamamoto et al. (18) & 2013 & 74 & M & Right buccal mucosa & No recurrence (4) \\
\hline Abé et al. (19) & 2014 & 46 & M & Left temporalis muscle & No recurrence (12) \\
\hline Sakamoto et al. (20)** & 2014 & 24 & F & Mandibular gingiva & NS \\
\hline Zhu et al. (21) & 2014 & 44 & F & Left soft palate and pharynx & NS \\
\hline Makarla et al. (22) & 2015 & 62 & M & Right buccal mucosa & Right buccal space \\
\hline Vazquez-Romero et al. (23) & 2017 & 32 & M & Left maxillary gingiva & No recurrence (12) \\
\hline & & 63 & M & Right buccal space & Possible recurrence (12); No \\
Witteveen et al. (24) & 2019 & & & & recurrence (48) \\
& & 48 & F & Left buccal space & No recurrence (12) \\
\hline Current cases & 2020 & 43 & F & Right maxillary gingiva & No recurrence (48) \\
\hline
\end{tabular}

* NS - not stated; ** Lynked to Gorlin-Goltz syndrome.

ting features as case 1 was located in the posterior maxillary gingiva and presented $15 \mathrm{~mm}$ in its largest diameter and case 2 affected a 63-year-old female.

Periapical and panoramic radiographs are essential in the diagnosis of any gengival swelling in order to exclude central intraosseous location of the lesion. To confirm the peripheral extraosseous location of the lesion no bone medullar destruction should be present, as shown in both present cases (21). In some cases, slight cortical saucer-shaped superficial resorption of the underlying bone can be seen, as shown in case 1 from this report, but integrity of the cortical bone should be observed.

As most POKC are located in the gingiva, differential diagnosis usually includes other odontogenic cysts that could affect this region, especially the gingival cyst of the adult and the peripheral calcifying odontogenic cyst. Both can produce a cup-shaped painless swelling filled by a bluish or bluish-gray fluid and superficial cortical bone resorption (9). The second location is the buccal mucosa and, in this site, cystic and cystic-solid salivary gland lesions should be considered in the clinical differential diagnosis. Histological analysis is the gold standard for POKC diagnosis. In the extraosseous location the same histological pattern described for conventional OKC should be present, as seen in the both present cases $(2,3,6,9,12,15,21)$.

Due to the limited number of reported cases, there is still some controversy on the biological behavior of POKC. As conventional intraosseous OKC can be locally infiltrative, presenting a higher local recurrence rate when comparing to other cysts, many therapeutic options have been suggested for this condition $(3,7,23)$. Nevertheless, it seems that POKC does not demonstrate the same aggressiveness and recurrence rates than central OKC. Therefore, its treatment will depend on the age of the patient, the location and size of the tumor, and whether it is a primary or recurrent tumor. Those characteristics justify the different therapeutic modalities for POKC reported in the literature, varying from conservative surgical removal - as performed in the present cases - to surgical removal with posterior curettage and a slight bone drilling of the area $(4,7,12,23)$. Follow-up is available for 18 reported POKC and shows a low recurrence rate (3 cases $-17 \%)$, whereas the remaining 15 cases $(83 \%)$ did not show any evidence of local recurrence in a mean of 27 months of follow-up (Table 1, 1 cont.) (3,6,9-12,14,16-19,22-24). Case 1 has been followed-up for 48 months with no signs of local recurrence.

In conclusion, POKC is a rare condition that mostly affects adults and can affect both the posterior and anterior gingival/alveolar mucosa. It can clinically mimic other peripheral odontogenic cysts and should be managed by conservative surgical removal.

\section{References}

1. Azevedo RS, Cabral MG, Dos Santos TC, Pires FR. Histopathological features of keratocystic odontogenic tumor: a descriptive study of 177 cases from a Brazilian population. Int J Surg Pathol. 2012;20:154-60.

2. Sanchez-Burgos R, Gonzalez-Martín-Moro J, Perez-Fernandez E, Burgueno-García M. Clinical, radiological and therapeutic features of keratocystic odontogenic tumours: a study over a decade. J Clin Exp Dent. 2014;6:e259-64.

3. Faustino SE, Pereira MC, Rossetto AC, Oliveira DT. Recurrent peripheral odontogenic keratocyst: a case report. Dentomaxillofac Radiol. 2008;37:412-4.

4. Stoelinga PJW, Cohen Jr MM, Morgan AF. The origin of keratocysts in the basal cell nevus syndrome. J Oral Surg. 1975;33:659-63.

5. Buchner A, Hansen LS. The histomorphologic spectrum of the gingival cyst in the adult. Oral Surg Oral Med Oral Pathol Oral Radiol Endod. 1979;48:532-9.

6. Dayan D, Buchner A, Gorsky M, Harel-Raviv M. The peripheral odontogenic keratocyst. Int J Oral Maxillofac Surg. 1988;17:81-3.

7. Chehade A, Daley TD, Wysocki GP, Miller AS. Peripheral odontogenic keratocyst. Oral Surg Oral Med Oral Pathol Oral Radiol Endod. 1994;77:494-7.

8. Fardal O, Johannessen AC. Rare case of keratin-producing multiple gingival cysts. Oral Surg Oral Med Oral Pathol. 1994;77:498-500.

9. Ide F, Shimoyama T, Horie N. Peripheral odontogenic keratocyst: a report of 2 cases. J Periodontol. 2002;73:1079-81. 
10. Chi AC, Owings Jr JR, Muller S. Peripheral odontogenic keratocyst: report of two cases and review of the literature. Oral Surg Oral Med Oral Pathol Oral Radiol Endod. 2005;99:71-8.

11. Preston RD, Narayana N. Peripheral odontogenic keratocyst. J Periodontol 2005;76:2312-5.

12. Ide F, Mishima K, Saito I, Kusama K. Rare peripheral odontogenic tumors: report of 5 cases and comprehensive review of the literature. Oral Surg Oral Med Oral Pathol Oral Radiol Endod. 2008;106:e22-8.

13. Precheur HV, Krolls SO. An unusual presentation of an odontogenic keratocyst in the buccal space: case report. J Oral Maxillofac Surg. 2009;67:2513-5.

14. Ide F, Kikuchi K, Miyazaki Y, Mishima K, Saito I, Kusama K. Keratocyst of the buccal mucosa: is it odontogenic? Oral Surg Oral Med Oral Pathol Oral Radiol Endod. 2010;110:e42-7.

15. Vij H, Vij R, Gupta V, Senqupta S. Odontogenic keratocyst: a peripheral variant. Niger J Clin Pract. 2011;14:504-7.

16. Gröbe A, Hanken H, Blessmann M, Zustin J, Heiland M, Al-Dam A. An odontogenic keratocystic tumor in the buccal space: an unusual site of origin and a review of the literature. In Vivo. 2012;26:847-51.

17. Kaminagakura E, Almeida JD, Carvalho YR, Franco RC, Soares FA, Rocha RM et al. Keratocyst of the buccal mucosa: case report and immunohistochemical comparative study with sporadic intraosseous keratocystic odontogenic tumor. Oral Surg Oral Med Oral Pathol Oral Radiol. 2013;116:e387-92.

18. Yamamoto K, Matsusue Y, Kurihara M, Takahashi Y, Kirita T. A keratocyst in the buccal mucosa with the features of keratocystic odontogenic tumor. Open Dent J. 2013;7:152-6.

19. Abé T, Maruyama S, Yamazaki M, Essa A, Babkair H, Mikami T et al. Intramuscular keratocyst as a soft tissue counterpart of keratocystic odontogenic tumor: differential diagnosis by immunohistochemistry. Hum Pathol. 2014;45:110-8.

20. Sakamoto K, Morita K, Shimada Y, Omura K, Izumo T, Yamaguchi A. Peripheral odontogenic keratocyst associated with nevoid basal cell carcinoma syndrome: a case report. Oral Surg Oral Med Oral Pathol Oral Radiol. 2014;118:e19-23.

21. Zhu L, Yang J, Zheng JW. Radiological and clinical features of peripheral keratocystic odontogenic tumor. Int J Clin Exp Med. 2014;7:3006.

22. Makarla S, Bavle RM, Muniswamappa S, Narasimhamurthy S. A large extragnathic keratocystic odontogenic tumour. Case Rep Pathol. 2015;2015:723010.

23. Vázquez-Romero MD, Serrera-Figallo ML, Alberdi-Navarro J, Cabezas-Talavero J, Romero-Ruiz MM, Torres-Lagares D et al. Maxillary peripheral keratocystic odontogenic tumor. A clinical case report. J Clin Exp Dent. 2017;9:e167-71.

24. Witteveen ME, Flores IL, Karssemakers LH, Bloemena E. Odontogenic keratocysts located in the buccal mucosa: a description of two cases and review of the literature. SAGE Open Med Case Rep. 2019;7:2050313X19849828.

\section{Ethics}

We state that we have followed the Helsinki declaration and that written permission was obtained from both patients included in the present report.

\section{Funding}

This work was supported by FAPERJ, Rio de Janeiro, Brazil.

\section{Authors' contributions}

Bruno Teixeira Gonçalves Rodrigues - conceptualization, data curation, investigation, methodology, software, roles/writing - original draft

Mônica Simões Israel - conceptualization, data curation, investigation, methodology, project administration, resources, software, supervision, validation, visualization, roles/writing - original draft, writing - review \& editing

Kenia Lorena Monteiro de Moura - data curation, formal analysis, investigation

Giulianna Lima Pinheiro - data curation, formal analysis, investigation
Roman Carlos - data curation, formal analysis, investigation, writing - review \& editing

Fábio Ramoa Pires - formal analysis, funding acquisition, supervision, validation, writing - review \& editing.

\section{Conflicts of interest}

None. 